\title{
INDICATIONS AND CONTRAINDICATIONS OF PHYSIOTHERAPY IN BREAST CANCER PATIENTS
}

\author{
BORDINC Ecaterina1, IRSAY Laszlo ${ }^{1,2}$ \\ ${ }^{1}$ Clinical Rehabilitation Hospital Cluj-Napoca \\ ${ }^{2}$ University of Medicine and Pharmacy Cluj-Napoca
}

\begin{abstract}
Breast cancer is a major public health issue. However, it is usually diagnosed when already at an advanced stage.

In developed countries, the mortality rate can be lowered through mammography screening so long as there is an infrastructure, funds and possibilities to allow the enforcement of specialty treatment. Such a program and good compliance to treatment can lower the mortality rate by up to $20 \%$ in women over 50 years of age.

It is compulsory that the malignity of the pathology is established prior to treatment in order for discussions regarding the tests required for establishing the pretreatment and therapy alternatives to be possible. Similarly to the other therapy options (surgery, chemotherapy, radiotherapy, hormone therapy, targeted therapy, etc.), medical rehabilitation plays an important role in establishing the patient's body function and quality of life.
\end{abstract}

Keywords: breast cancer, physiotherapy, indications, contraindications

\section{Incidence:}

In Romania, this is the most frequently encountered malignant tumor in women with approximately 4,200 new cases and 2,500 deaths registered every year. The numbers are expected to increase even further, but it must be noted that the mortality rate has stagnated at $60-70 \%$ over the past 20 years. [1, 2, 3, 4]

\section{The importance of physiotherapy:}

The course of treatment is established based on the stage of the disease and the associated defects and can consist of one or a combination of the following methods: surgery, chemotherapy, radiotherapy, hormone therapy, targeted therapy, medical rehabilitation, etc.

Postoperative management - It is very important that the therapist makes contact with the patient shortly after surgery for the latter to acquire the selfcare steps as rapidly as possible.

Such surgical interventions are associated with short hospitalization times, so the therapist should make contact with the patient the following day and highlight the importance of preventing complications, disabilities and postoperative function limitations (lung complications, upper limb lymphedema, mobility impairment, etc.).

The main objectives of medical rehabilitation include: pain management frequently neuropathic or secondary to chemotherapy or post-mastectomy, improved scapulohumeral mobility, improved muscle strength, lymphedema reduction, ADL resumption, playing an important role in establishing the patient's body function and quality of life.

Physical medicine and rehabilitation programs improve the quality of life by reducing fatigue, increasing physical functionality and improving pain or dyspnea.

A relevant number of studies were conducted between 2001 and 2011 to identify general principles regarding the rehabilitation of patients diagnosed with breast cancer. One of the basic principles addresses the rehabilitation of the upper limb. 


\section{Postoperative complications that require rehabilitation techniques:}

- Lung complications or immediate or late blood flow complications

- Upper limb lymphedema

- Upper extremity mobility impairment

- Defective posture alignment

- Reduced muscle strength and function of the upper extremity

- Fatigue and low physical endurance

- Emotional and social adaptation difficulties [5]

Objectives of the medical rehabilitation program:

$>$ The correction of functional deficiencies signaled during ADL (activities of daily living) driving, sleeping, child care, posture deformation correction.

In the short run, a significant reduction of the motor area of the shoulder can be identified after a period of 2-3 months after the mastectomy. [6] In the long run, a reduction of the motor area of the shoulder can occur in $28 \%$ of cases after a period of 1 year after the mastectomy and a significant decrease in muscle strength required for shoulder flexion and abduction after a period of 15 months after the mastectomy. [7]

\section{Exercise therapy (Kinetotherapy): Objectives:}

1. Preparing the patient for postoperative self-management.

2. The prevention of postoperative lung complications and thromboembolism: Deep breathing exercises with special emphasis on maximum inspiratory flows and efficient coughing. Flexion exercises for the lower limb.

3. The prevention or minimization of the risk of postoperative lymphedema: Elevation of affected extremities on pillows (at a 30degree angle) while the patient is sitting on a bed or chair. The application of bandages around the affected arm or that of elastic compression bandages. The elevation of the affected arm. Exercises designed to increase the amplitude of movement. The avoidance of upper limb immobilization.

4. The reduction of the degree of lymphedema if or when it occurs: Daily use of the pneumatic compression pump followed by wrapping of the upper limb. Permanent elevation of the entire upper limb when the patient is at ease. Continuous wrapping of the upper limb in non-elastic or partially elastic compression bandages (whether the patient is active or at ease). Manual lymphatic drainage massage. Daily routines for lymphedema reduction. Use of compression bandages after the routine for lymphedema reduction and stabilization. Careful nursing of the tegument.

5. The prevention of posture deformation: Preparation regarding the correct position in bed with the central and symmetrical positioning of the shoulders in relation to the trunk prior to surgery or on the same day. Posture acknowledgement training: encouraging the patient to adopt a correct position in order to avoid an abnormal shoulder position. Posture exercises with a focus on scapular retraction exercises.

6. The prevention of blood pressure problems and cervical muscle contraction or retraction: Exercises designed to increase the amplitude of movement in the cervical area and relaxation. Shoulder elevation and rotation exercises. Soft massage at the level of the cervical muscles.

7. The prevention of joint stiffness in the upper extremity: Exercises 
designed to increase the amplitude of movement at the level of the shoulders, elbows and hands. The routine must be initiated as soon after surgery as possible. It can also be initiated in the presence of drainage tubes, but maximum attention is required. Once the incision has healed, stretching exercises can be conducted at shoulder level.

8. The recovery of muscle strength and upper limb function: Lowintensity isometric exercises at shoulder level initiated on postoperative day 1 or 2 . Resistance exercises conducted with lightweights or partially elastic materials which act on the scapular or glenohumeral muscles. Scapular or glenohumeral stabilization through exercises conducted in orthostatic position, hands pressed against the wall or table. Use of affected limb for lowintensity daily activities.

9. Increasing the patient's effort tolerance, well-being and thus reducing fatigue: Low-intensity aerobic exercises such as aerobics or gait.

10. The provision of information regarding the patient's resources, provision of support from the family and her continuous education.

Precautions: The shoulder exercises must be conducted at an elevation angle of up to 90 degrees until after the removal of the drainage tubes. The stitches and incisions must be monitored carefully during exercise. The difficulty of exercises must be increased gradually and very slowly, especially if the patient undergoes adjuvant therapy. [5]

\section{Clinical guideline recommendations for the upper limb:}

The function of both upper limbs must be evaluated prior to surgery in order to have a point of comparison.
Exercise therapy (Kinetotherapy) must be initiated on postoperative day 1. A mild routine should be conducted starting postoperative week 1 . The active exercises can be initiated after a period of 1 week after surgery, once the drainage tubes have been removed. It is recommended that they be continued for a period of 6-8 weeks until the full range of motion of the upper limb has been restored. The patient must be trained to massage the scarred area herself. The postoperative clinical assessment should be regulated within a year after surgery. [5]

Progressive resistance exercises can be conducted using lightweights (0.5$1 \mathrm{~kg}$ ) between postoperative weeks 4 and 6. It is important to provide careful nursing, a proper hygiene of the upper limb and avoid trauma in order to minimize the risk of infection and lymphedema.

It is important for the patient to maintain an optimal level of activity after surgery, initiate a resistance exercise routine and conduct average-intensity exercises for 30 minutes on a number of days per week. This routine should also include exercise therapy (Kinetotherapy) and occupational therapy.

The physical routine must be established according to the patient's gender, age and type of cancer, among others. Also, the intensity and duration of the exercises should be set low initially and then increased gradually.

Studies have also revealed that physical exercise lowers the risk of femoral neck fracture, probably by lowering the risk of falls. However, it has a low effect in terms of mineral bone density preservation. The routine must be conducted on a daily basis with at least 30 minutes of moderate physical activity included.

Tai chi, physical therapy and dancing are considered good options to improve balance and prevent falls. 
Studies have demonstrated that physical activity is mainly associated with an improved quality of life at both physical and functional levels. A combination between physical activity and cognitive-behavioral therapy can determine a significant improvement in the patient's quality of life. The results of the physical exercise programs become visible within a short period of time after the initiation of the program. In the long run, better results can be obtained by combining physical exercise and psychological therapy. A comparative study demonstrated the long-term benefits of physical exercise on the well-being of breast cancer patients as well as the beneficial effects of a program that combines physical exercise and cognitivebehavioral therapy. [8] Two different studies have emphasized the importance of long-term physical exercise in improving the quality of life of breast cancer patients. The studies conducted by Milne et al. (2008) revealed a significant improvement in the quality of life of the participants after following a 12-week program consisting of combined aerobic and resistance exercises. Daley et al. (2007) highlighted the beneficial effect of an 8-week program involving regular physical exercise on breast cancer patients. A significant improvement in their overall mobility could be noticed upon every assessment.

Recent (randomized and controlled) trials have demonstrated that upper limb exercises do not influence the occurrence or increase in volume of lymphedemas.

The intense activity of the upper limb affected after surgery or axillary dissection does not appear to have any influence on the development or occurrence of lymphedemas. [9, 10, 11, 12]

A recent study conducted by Torres Lacomba et al. compared the benefits of medical rehabilitation associated with medical education initiated between postoperative days 3 and
5 and those of medical education only. The medical rehabilitation techniques included manual lymphatic drainage, stretching exercises, resistance exercises and the treatment of axillary web syndrome (AWS), in the event of its occurrence. The study revealed a tight connection between the axillary web syndrome, the increased risk of lymphedema and the possibility to prevent it through the early initiation of recovery therapy. Research is still being conducted at present to identify the therapy components that can treat postoperative complications and the benefits of manual therapy in the immediate postoperative period. [13]

Chemotherapy can trigger the development of peripheral neuropathies. According to various studies, TENS (Transcutaneous Electrical Nerve Stimulation), acupuncture, exercise therapy (Kinetotherapy) and occupational therapy can all be used in these cases, along with therapeutic interventions and medical education.

Three minor studies conducted on patients who performed progressive resistance and stretching exercises (loading the muscles antagonist to those affected by neuropathy) showed a significant improvement in function, action and nerve conduction velocity of the peroneal and sural nerve in peripheral neuropathy and muscle dystrophy treatment. The physiotherapist must insist on muscle toning exercises with or without the association of bio-feedback techniques, proprioception facilitation or stimulation. Braces are useful for the consolidation of stability and security in patients with motor deficiencies (they protect and stabilize the joints controlled by weak muscles, maintain the joints in functional positions and complete the motor function that has been lost). [14]

\section{Alternative methods:}

Acupuncture is another alternative treatment method. A case study conducted 
on a small number of patients revealed that this treatment method led to improved sensitive and motor functions, as well lower doses of analgesics being given. No side effects were noticed. [14]

\section{Electrotherapy:}

\begin{tabular}{|c|c|c|}
\hline \multicolumn{3}{|r|}{ their use. [J] } \\
\hline \multicolumn{2}{|c|}{ TYPE OF PROCEDURE } & RECOMMENDATION \\
\hline \multirow[t]{2}{*}{ ULTRASOUND } & CONTINUOUS & $\begin{array}{l}\text { LOCALLY CONTRAINDICATED in } \\
\text { cases of suspected or proven malignity and } \\
\text { in patients with a breast cancer history in } \\
\text { the past } 5 \text { years presenting with pain } \\
\text { without the precise etiology being identified }\end{array}$ \\
\hline & PULSATILE & $\begin{array}{l}\text { LOCALLY CONTRAINDICATED in } \\
\text { cases of suspected or proven malignity and } \\
\text { in patients with a breast cancer history in } \\
\text { the past } 5 \text { years presenting with pain } \\
\text { without the precise etiology being identified }\end{array}$ \\
\hline \multirow[t]{3}{*}{$\begin{array}{l}\text { ELECTRICAL } \\
\text { STIMULATION }\end{array}$} & TENS & $\begin{array}{l}\text { LOCALLY CONTRAINDICATED in } \\
\text { cases of suspected or proven malignity, it } \\
\text { can be used for pain management purposes } \\
\text { in patients undergoing palliative care. } \\
\text { However, the antialgic effect may conceal } \\
\text { the first signs of metastasis. }\end{array}$ \\
\hline & NMES & $\begin{array}{l}\text { LOCALLY CONTRAINDICATED in } \\
\text { cases of suspected or proven malignity, it } \\
\text { can improve the quality of life in terminal } \\
\text { patients }\end{array}$ \\
\hline & HVPC & $\begin{array}{l}\text { LOCALLY CONTRAINDICATED in } \\
\text { cases of suspected or proven malignity and } \\
\text { in patients with a breast cancer history in } \\
\text { the past } 5 \text { years presenting with pain } \\
\text { without the precise etiology being identified }\end{array}$ \\
\hline \multicolumn{2}{|c|}{ LLLT LIGHT } & $\begin{array}{l}\text { LOCALLY CONTRAINDICATED in } \\
\text { cases of suspected or proven malignity and } \\
\text { in patients with a breast cancer history in } \\
\text { the past } 5 \text { years presenting with pain } \\
\text { without the precise etiology being identified }\end{array}$ \\
\hline \multicolumn{2}{|c|}{ THERMAL SWT (>30-40 WATTS) } & $\begin{array}{l}\text { LOCALLY CONTRAINDICATED } \\
\text { cases of suspected or proven malignity }\end{array}$ \\
\hline \multicolumn{2}{|c|}{ NON-THERMAL SWT (<34 WATTS) } & $\begin{array}{l}\text { LOCALLY CONTRAINDICATED } \\
\text { cases of suspected or proven malignity }\end{array}$ \\
\hline
\end{tabular}

ABBREVIATIONS: TENS (TRANSCUTANEOUS ELECTRICAL NERVE STIMULATION), NMES (NEUROMUSCULAR ELECTRICAL STIMULATION), HVPC (HIGH-VOLTAGE PULSED CURRENT), LLLT (LOW-LEVEL LASER THERAPY-NON COHERENT LIGHT), SWT (SHORT WAVE TERAPY)
LASER (light amplification by stimulated emission of radiation) treatment and electric stimulation are not recommended during the immediate postoperative period and in the proximity of the neoplasm, based on the insufficiency of clinical data to support their use. [5] in patients with a breast cancer history in the past 5 years presenting with pain cases of suspected or proven malignity and in patients with a breast cancer history in the past 5 years presenting with pain LOCALLY CONTRAINDICATED in cases of suspected or proven malignity, it can be used for pain management purposes LOCALLY CONTRAINDICATED in (it patients cases of suspected or proven malignity and in patients with a breast cancer history in the past 5 years presenting with pain LOCALLY CONTRAINDICATED in cases of suspected or proven malignity and in patients with a breast cancer history in without the precise etiology being identified LOCALLY CONTRAINDICATED in LOCALLY CONTRAINDICATED in cases of suspected or proven malignity LOCALLY CONTRAINDICATED in

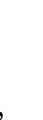


Continuous ultrasound therapy can generate perceivable heat at tissue level whereas its pulsatile counterpart does not usually cause this reaction; HPVC - highvoltage pulsed current (it is used for the stimulation of chronic injury healing and applied at sensory or subsensory stimulation level); NMES - neuromuscular electrical stimulation (it uses the stimulation parameters required to generate a tetanic contraction of the muscles); TENS - transcutaneous electrical nerve stimulation (it is applied at sensory level and produces a paresthetic sensation with the purpose of triggering analgesia or hypoanalgesia); LLLT - low-level laser therapy $(<500 \mathrm{mV}-$ it involves all lasers and non-coherent light sources belonging to Class II and Class III); SWT - short wave therapy (in thermal doses, it generates perceivable heat at tissue level, increasing their temperature by a minimum of 1 degree Celsius; in non-thermal doses, it does not generate perceivable heat at tissue level, but may increase their temperature). $16,17,18,19,20,21,22,23,24,25,26,27,28,29$ ,30,31,32,33,34,35,36,37,38,39]

\section{Hydrotherapy:}

Hydrotherapy constitutes a comprehensive approach to physical exercise in water designed to increase strength, flexibility, resistance, blood flow and muscle relaxation.

Water based exercise is not contraindicated. However, sauna and thermotherapy are not recommended. Underwater showers and compressed air baths can be recommended, while peloids are recommended for distant affections (e.g. knee or hip disorders). [8]

\section{Thermotherapy:}

Thermotherapy involves hot compresses, wax and other artificial heating agents which can increase tissue temperature to a depth of $3 \mathrm{~cm}$. [15]

Microwaves and thermotherapy are not recommended during the immediate
THERMOTHERAPY (hot compresses, wax and other artificial heating agents)

LOCALLY CONTRAINDICATED in cases of suspected or proven malignity and in patients with a breast cancer history in the past 5 years presenting with pain without the precise etiology being identified

postoperative period and in the proximity of the neoplasm. [5]

\section{Cryotherapy:}

\section{CRYOTHERAPY RECOMMENDED}

Cryotherapy involves cold compresses, ice packs, ice baths, ice massaging, etc. $[15,40]$

\section{Conclusion:}

It has been demonstrated that medical rehabilitation does not affect the evolution of breast cancer and takes into consideration the TNM (tumor, lymph nodes, metastasis) classification.

Its main objectives include pain management - frequently neuropathic or secondary to chemotherapy or postmastectomy, improved scapulohumeral mobility, improved muscle strength, lymphedema reduction, ADL resumption, etc.

Numerous recent studies have demonstrated the major utility of physiotherapy and the need to initiate it as soon after surgery as possible.

Recent studies have demonstrated the importance of early exercise therapy (Kinetotherapy) initiation in improving the quality of life by reducing fatigue, increasing physical functionality and improving pain or dyspnea.

Based on a large body of evidence published in recent years, including randomized trials and systematic reviews, there is an urgent need for updating the guidelines on upper extremity musculoskeletal impairments and 
lymphedema. Furthermore, additional research is needed to provide an evidence base for developing rehabilitation guidelines on the management of other impairments identified in the prospective surveillance model, e.g. arthralgia.

To conclude: "Learning to live with cancer is an art, not a science. Each person must find her own way, in her own style. What is important to realize is that a way can be found regardless of the circumstances and prospects." Jane Brody

\section{References:}

1. Ferlay, J., Soerjomataram, I., Ervik, M. et al., GLOBOCAN 2012, v1.0, Cancer incidence and mortality worldwide: IARC CancerBase, No.11, Lyon, France: International Agency for Research on Cancer, 2013. Available from: http://globocan. iarc.fr, accessed December 2013;

2. Anderson, F., Jatoi, I., Tse, J., Rosenberg, S. Male breast cancer. A population-based comparison with female breast cancer. J Clin Oncol, 2010;28,232-239;

3. Contractor, KB, Kaur, K., Rodrigues, GS, Kulkarni, DM, Singhal, H. Male breast cancer: is the scenario changing. World J Surg Oncol., 2008; 6:58;

4. Rossman, E., Libjegren, A., Bergh, J. Male breast cancer- how to treat? Breast Cancer online, 2007;10:1- 6;

5. Harris, SR, Schmitz, KH, Campbell, KL, McNeely, ML. Clinical practice guidelines for breast cancer rehabilitation: syntheses of guideline recommendations and qualitative appraisals. Cancer 2012;118 (8 suppl.): 2312-2324;

6. Gosselink, R., Rouffaer, L., Vanhelden, P., Piot, W., Troosters, T., Christiaens, MR. Recovery of upper limb function after axillary dissection. Journal Surg Oncol., 2003;83(4):204-211;
7. Blomqvist, L., Stark, B., Engler, N., Malm, M. Evaluation of arm and shoulder mobility and strength after modified radical mastectomy and radiotherapy. Acta Oncologica, 2004:43(3):280-283;

8. May, A., Korstjens, I., Van Weert, E., Van den Borne, B. Long-term effects on cancer survivors' quality of life of physical training versus physical training combined with cognitive-behavioral therapy: results from a randomized trial. Support Care Cancer, 2009;17(6):653-663;

9. Milne, HM, Wallman, KE, Gordon, S., Courneya, KS. Effects of a combined aerobic and resistance exercise program in breast cancer survivors. A randomized controlled trial. Breast Cancer ResTreat, 2008;108(2):279-288;

10. Daley, AJ, Crank, H., Saxton, JM, Mutrie, N., Coleman, R., Roalfe, A. Randomized trial of exercise therapy in women treated for breast cancer. $\mathrm{J}$ Clin Oncol, 2007;25(13):1713-172;

11. Aaronson, N., Turo, AM. Pilates, yoga and Reiki master. MAOT Annual Conference, 2010;

12. Bavaria, M. Contraindications in physical rehabilitation-doing no harm. Saunders Elsevier, 2006;10(14):839-856;

13. Torres Lacomba, M., Yuste Sánchez, MJ, Zapico Goni, A. et al. Effectiveness of early physiotherapy to prevent lymphedema after surgery for breast cancer: randomized, single blinded, clinical trial. BMJ, 2010;340:b5396-b5404;

14. Visovsky, C., Collins, M., Abbott, L., Aschenbrenner, J., Hart, C. Putting evidence into practice. Evidencebased interventions for chemotherapy-induced peripheral neuropathy. Clin J Oncol. Nurs. 2007;11(6):901-913;

15. Houghton, E. P., Nussbaum, E. L., Hoens, M. A. Physiotherapy Canada 
- Electrophysical agents contraindications and precautions: an evidence-based approach to clinical decision making in physical therapy, 2010, Volume 62, no. 5, 5-66.

16. Delpizzo V, Joyner K. On the safe use of microwave and shortwave diathermy units. Aust J Physiother. 1987;33:152-61.

17. Shields N, O'Hare N, Gormley J. Contra-indications to shortwave diathermy: survey of Irish physiotherapists.

Physiotherapy.2004;90:42-53.

18. Shields N, Gormley J, O'Hare N. Short-wave diathermy: current clinical and safety practices. Physiother Res Int. 2002;7:191-202.

19. Shields N, O'Hare N, Boyle G, Gormley J. Developnment and application of a quality control procedure for short-wave diathermy units. Med Biol Eng Comp. 2003;41:62-8.

20. Shields N, Gormley J, O'Hare N. Physiotherapist's perception of risk from electromagnetic fields. $\mathrm{Adv}$ Physiother. 2005:170-5.

21. Carmeliet P, Jain RK. Angiogenesis in cancer and other diseases. Nature. 2000;407:249-57.

22. Logan ID, McKenna PG, Barnett YA. An investigation of the cytotoxic and mutagenic potential of low intensity laser irradiation in Friend Erythroleukemia cells. Mutat Res Lett. 1995;347(2):67-71.

23. Corti L, Chiarion-Sileni V, Aversa S, Ponzoni A, D'Arcais R, Pagnutti S, et al. Treatment of chemotherapy- induced oral mucositis with lightemitting diode. Photomed Laser Surg. 2006;2:207-13.

24. Schaefer N, Schafer H, Maintz D, Wagner M, Overhaus M, Hoelischer $\mathrm{AH}$, et al. Efficacy of direct electrical therapy and laser induced interstitial thermotherapy in local treatment of hepatic colorectal metastases: an experimental model in the rat.J Surg Res. 2008;146:230.

25. Bauer W. Electrical treatment of severe head and neck cancer pain. Arch Otolaryngol. 1983;109:382-3.

26. Bausewein C, Booth S, Gysels M, Higginson I. Non-pharmacological interventions for breathlessness in advanced stages of malignant and non-malignant diseases. Cochrane $\mathrm{Db}$ Syst Rev.;2008:2.

27. Crevenna R, Marosi C, Schmidinger M, Fialka-Moser V. Neuromuscular electrical stimulation for a patient with metastatic lung cancer-a case report. Support Care Cancer. 2006;14:970.

28. Reuss R, Meyer SC. The use of TENS in the management of cancer pain. Clin Manag Phys Ther. 1985;5:26-8.

29. Carmeliet P, Jain RK. Angiogenesis in cancer and other diseases. Nature. 2000;407:249-57.

30. Maxwell L. Therapeutic ultrasound and tumour metastasis. Physiotherapy. 1995;81:272-5.

31. Maxwell L. Therapeutic ultrasound and the metastasis of a solid tumour. J Sport Rehabil. 1995;4:273-81. 
32. Oakley EM. Dangers and contraindications of therapeutic ultrasound. Physiotherapy. 1978;64:173-4;

33. Sicard-Rosenbaum L, Lord D, Danoff J, Thom A, Eckhaus M.Effects of continuous therapeutic ultrasound on growth and metastasis of subcutaneous murine tumors. Phys Ther. 1995;75:3.

34. Quan KM, Shiran M, Watmough DJ. Applicators for generating ultrasound-induced hyperthermia in neoplastic tumours and for use in ultrasound physiotherapy. Phys Med Biol. 1989;34:1719.

35. Smachlo K, Fridd CW, Child SZ, Hare JD, Linke CA, Carstensen EL. Ultrasonic treatment of tumors, I: absence of metastases following treatment of hamster fibrosarcoma. Ultrasound Med Biol. 1979;5:45-9.

36. Maddocks M, Lewis M, Chauhan A, Manderson C, Hocknell J, Wilcock A. Randomized controlled pilot study of neuromuscular electrical stimulation of the quadriceps in patients with non-small cell lung cancer. J Pain Symptom Manag. 2009;38:950-6.

37. Bennett $\mathrm{M}$, Johnson $\mathrm{M}$, Brown $\mathrm{S}$, Radford H, Brown J, Searle D.Feasibility study of transcutaneous electrical nerve stimulation (TENS) for cancer bone pain. $J$ Pain. 2010;11:351-9.

38. Robertson VJ, Chipchase LS, Laakso EL, Whelan KM, McKenna LJ. Guidelines for the clinical use of electrophysical agents. Camberwell, VIC: Australian Physiotherapy Association; 2001.

39. Guidance for the clinical use of electrophysical agents. London: Chartered Society of Physiotherapy; 2006.

40. Bowsher D, Haggett C. Paradoxical burning sensation produced by cold stimulation in patients with neuropathic pain. Pain.2005;117:230. 